Research Article

\title{
Contributions of Fasting and Postprandial Glucose Concentrations to Haemoglobin A1c in Drug-Naïe Mal-Glucose Metabolism in Chinese Population Using Continuous Glucose Monitoring System
}

\author{
Rengna Yan, ${ }^{1}$ Yun Hu ${ }^{D},{ }^{1}$ Fengfei Li ${ }^{(D)},{ }^{1}$ Lanlan Jiang,, Xiaohua Xu, ${ }^{1}$ Jie Wang, \\ Ying Zhang, ${ }^{1}$ Lei Ye $\mathbb{D},{ }^{2}$ Kok Onn Lee, ${ }^{3}$ Xiaofei Su $\mathbb{D},{ }^{1}$ and Jianhua Ma $\mathbb{D}^{1}$ \\ ${ }^{1}$ Department of Endocrinology, Nanjing First Hospital, Nanjing Medical University, Nanjing 210012, China \\ ${ }^{2}$ National Heart Research Institute Singapore, National Heart Centre Singapore, Singapore 169609 \\ ${ }^{3}$ Department of Medicine, National University of Singapore, Singapore 119228 \\ Correspondence should be addressed to Xiaofei Su; suxiaofeifei@126.com and Jianhua Ma; majianhua196503@126.com
}

Received 27 August 2019; Accepted 29 October 2019; Published 1 December 2019

Academic Editor: Pawel Grzmil

Copyright (c) 2019 Rengna Yan et al. This is an open access article distributed under the Creative Commons Attribution License, which permits unrestricted use, distribution, and reproduction in any medium, provided the original work is properly cited.

\begin{abstract}
Aim. To clarify the contributions of fasting glucose (FG) and postprandial glucose (PG) to HbAlc in drug-naïve patients with type 2 diabetes (T2D) and impaired glucose tolerate (IGT)/impaired fasting glucose (IFG). Methods. Continuous glucose monitoring (CGM) was performed in 305 drug-naïve Chinese patients with T2D or IGT/IFG. The incremental area under the curve (AUC) above a glucose value of $6.1 \mathrm{mmol} / \mathrm{L}$ or FG glucose levels were calculated to evaluate the contributions of PG or FG to HbA1c values. Results. According to quintiles of $\mathrm{HbA1c}$, T2D patients were divided into five groups (group 1 to 5), and patients with IGT/ IFG were assigned into group 0. PG was the predominant contributor in the lower groups with HbA1c 4.9 6.0\% and 6.1 7.8\%. The relative contributions of FG and PG to HbA1c had no significance in the middle groups of HbA1c (7.9 8.7\% and 8.8 9.5\%). FG contributed significantly more than PG in the higher groups of HbA1c (9.6 10.9\% and 11.0 14.6\%). Regression analyses indicate that the contributions of FG and PG were equal (both 50\%) when the level of HbA1c was 8.5\%. Conclusions. In drug-naïve patients with T2D or IGT/IFG, PG contributed more in patients with HbA1c $<8.5 \%$, whereas FG became the predominant contributor in the poorly controlled patients with $\mathrm{HbA1c} \geq 8.5 \%$. These results may help the health-care provider set appropriate plasma glucose testing goals with the expectation of achieving specific HbAlc values.
\end{abstract}

\section{Introduction}

Glycemic control is a cornerstone in delaying the onset and decreasing the incidence of both the short- and long-term complications of diabetes. Glycated haemoglobin (HbA1c) is a gold-standard parameter in evaluating the effectiveness of glycaemic control in patients with diabetes [1]. The Diabetes Control and Complication Trial (DCCT) and the United Kingdom Prospective Diabetes Study (UKPDS) indicated that $\mathrm{HbAlc}>7.0 \%$ is associated with a significantly increased risk of both microvascular and macrovascular complications, regardless of underlying treatment [2-5].
Fasting glucose (FG) and postprandial glucose (PG) are commonly used as daily makers to evaluate glycaemic control and modify therapeutic strategy. Clearly understanding the relationship between plasma glucose levels and $\mathrm{HbAlc}$ will help to set appropriate day-to-day plasma glucose testing goals for achieving the target $\mathrm{HbAlc}$ level. There is no consensus about the association between FG and PG with $\mathrm{HbAlc}$ in patients with type 2 diabetes (T2D) [6-14]. Most previous studies were based on multipoint glucose measurements in treated patients. In this study, we evaluate the contribution of FG and PG on HbAlc in newly diagnosed and untreated patients with T2D or IGT/IFG 
using continuous glucose monitoring systems (CGMS). This may help to identify the better surrogate glycemic marker for achieving the target $\mathrm{HbA1c}$ level and for early detection of glycemic control status.

\section{Materials and Methods}

2.1. Subjects. According to 1999 WHO diagnostic criteria [15], DM was defined as fasting plasma glucose $\geq 7.0 \mathrm{mmol} /$ $\mathrm{L}$ and/or $2 \mathrm{~h} P G \geq 11.1 \mathrm{mmol} / \mathrm{L}$. Impaired Glucose Tolerance (IGT) was defined as fasting plasma glucose $<7.0 \mathrm{mmol} / \mathrm{L}$ and $2 \mathrm{~h} \mathrm{PG} \geq 7.8 \mathrm{mmol} / \mathrm{L}$. Impaired Fasting Glycaemia (IFG) was defined as fasting plasma glucose $\geq 6.1$ to $<7.0$ and $2 \mathrm{~h} \mathrm{PG}<7.8 \mathrm{mmol} / \mathrm{L}$. A total of 305 newly diagnosed, drug-naïve patients with T2D or IGT/IFG were recruited between January 2015 and December 2018 in Nanjing First Hospital, Nanjing Medical University, China. The inclusion criteria were newly diagnosed, drug-naive patients with T2D or IGT/IFG. Patients who had ketoacidosis, impaired renal (serum creatinine $>150 \mu \mathrm{mol} / \mathrm{L}$ ) or liver (aspartate aminotransferase or alanine aminotransferase 2.5 times the upper limit of the normal range) functions or a history of anaemia, or suffered from cancer were excluded. The study was approved by the ethics committee of Nanjing Hospital. Informed consents were signed by all patients. The methods were conducted in accordance with the Declaration of Helsinki guidelines, including any relevant details.

2.2. Clinical and Laboratory Assessments. After admission, detailed interviews and regular laboratory analyses were performed in all patients. Anthropometric parameters of height, weight, waist circumference, hip circumference, and blood pressure were measured, and recorded BMI was calculated as body weight divided by height squared $\left(\mathrm{kg} / \mathrm{m}^{2}\right)$. $\mathrm{HbAlc}$ was analyzed using high-performance liquid chromatography (Bio-Rad, USA). Serum creatinine, liver functional parameters (aspartate aminotransferase and alanine aminotransferase), and lipid profiles (total cholesterol, triglycerides, high- and low-density lipoproteins) were measured by enzymatic assays (Olympus AU5400 autoanalyzer; Beckman Coulter, Japan).

2.3. Food Intake. All subjects were instructed to maintain physical activity according to their doctors' personalized instructions and received meals consisting of a total daily caloric intake of $25 \mathrm{kcal} / \mathrm{kg} / \mathrm{day}$. The ratio of carbohydrate, proteins, and fats were $55 \%, 17 \%$, and $28 \%$, respectively. Patients were instructed to have breakfast, lunch, and dinner at 7:00 AM, 11:00 AM, and 5:00 PM, respectively.

2.4. Calculation of the Relative Contributions of PG and FG to A1c Levels. A retrospective CGMS (Sofsensor, CGMS-Gold, Medtronic Incorporated, Northridge, USA) [16] was applied to the recruited patients 72 hours before glycemic control treatment. To minimize the influence of diet taken before hospital admission, the contributions of FG and PG to overall hyperglycaemia was calculated using CGMS data obtained in the second 24 hours $(24 \mathrm{~h})$ after admission. Blood glucose level $>6.1 \mathrm{mmol} / \mathrm{L}$ is considered as hyperglycemia. We defined the glucose area under the curve (AUC) above $6.1 \mathrm{mmol} / \mathrm{L}$ during the second 24-h interval as $\mathrm{AUC}_{\text {total }}$ to represent overall hyperglycaemia [13]. The glucose AUC above FG was defined as $\mathrm{AUC}_{\mathrm{PG}}$ reflecting the contribution of PG to overall hyperglycaemia during $24 \mathrm{~h}$. The $\mathrm{AUC}_{\mathrm{FG}}$ was defined as $\mathrm{AUC}_{\text {total }}-\mathrm{AUC}_{\mathrm{PG}}$. The relative contributions of $\mathrm{FG}$ and $\mathrm{PG}$ to overall hyperglycaemia were calculated as $\left(\left(\mathrm{AUC}_{\mathrm{total}}-\mathrm{AUC}_{\mathrm{PG}}\right) /\right.$ $\left.\mathrm{AUC}_{\text {total }}\right) \times 100 \%$ and $\left(\mathrm{AUC}_{\mathrm{PG}} / \mathrm{AUC}_{\text {total }}\right) \times 100 \%$, respectively [14]. The HbA1c values used for analysis in this study were those obtained at admission. According to quintiles of HbAlc, the subjects with diabetes were divided into five groups (from 1 to 5 ) and patients with IGT/IFG were allocated into group 0 to evaluate the contribution of FG and PG to glucose increments.

2.5. Statistical Analysis. All statistical analyses were performed using the SPSS statistical program, version 16.0 (SPSS, Chicago, IL, USA). The data are shown as mean \pm SD or percentage. Parameters of AUC and other relative clinic data were compared over groups of HbAlc using one-way ANOVA, followed by Bonferroni's test. Relative contributions of FG and PG were compared using a paired Student's $t$ test. $P<0.05$ was considered significant.

\section{Results}

The clinical characteristics and demographics of subjects with prediabetes and diabetes according to the quintiles of HbA1c are shown in Table 1. A total of 305 patients (208 men and 97 women) with newly diagnosed T2D or IGT/IFG were recruited. Their mean age was $51.1 \pm 11.4$ years, mean body mass index (BMI) was $25.3 \pm 3.5 \mathrm{~kg} / \mathrm{m}^{2}$, and mean HbA1c was $9.3 \pm 1.9 \%$ (range $4.9-14.6 \%$ ).

All the AUC results calculated from CGM are indicated in Table 1 and Figure 1. The level of FG, the overall hyperglycemia $\left(\mathrm{AUC}_{\text {total }}\right)$, and fasting glucose increments $\left(\mathrm{AUC}_{\mathrm{FG}}\right)$ were increased from the lowest to the highest groups of $\mathrm{HbA1c}$, especially in the higher groups. However, $\mathrm{AUC}_{\mathrm{PG}}$, which reflects postprandial glucose increments, almost remained stable over the higher groups. In the lowest group, IGT/IFG group, $A_{U C}$ and $A_{P U} C_{F G}$ were both smallest. In lower group $1, \mathrm{AUC}_{\mathrm{PG}}$ was slightly above $\mathrm{AUC}_{\mathrm{FG}}$. In quintiles 2 and $3, \mathrm{AUC}_{\mathrm{FG}}$ was higher than $\mathrm{AUC}_{\mathrm{PG}}$ with the difference of 1.0 and $0.5 \mathrm{mmol} / \mathrm{L} \cdot$ day, respectively. In the higher quintiles 4 and 5, the difference between $\mathrm{AUC}_{\mathrm{FG}}$ and $\mathrm{AUC}_{\mathrm{PG}}$ increased to 2.0 and $2.2 \mathrm{mmol} / \mathrm{L} \cdot$ day, respectively.

The relative contribution of FG and PG is shown in Figure 2. PG contributed to hyperglycemia more than FG in the lowest HbAlc groups (range: $4.9-6.0 \%$, mean: $5.5 \pm 0.4 \%$ and range: $6.1-7.8 \%$, mean: $7.3 \pm 0.5 \%)$. FG and PG equally contributed to hyperglycemia in groups 2 and 3 (range: $7.9-8.7 \%$, mean: $8.3 \pm 0.3 \%$ and range: $8.8-9.5 \%$, mean: $9.1 \pm 0.2 \%$ ). In the highest HbAlc quintiles 4 and 5 (range: 9.6-10.9\%, mean: $10.1 \pm 0.4 \%$ and range: $11.0-14.6 \%$, mean: $12.1 \pm 0.9 \%)$, fasting hyperglycemia began to play a major role in the contribution to hyperglycemia. 
TABLE 1: Characteristics of all prediabetes and T2D patients over groups of HbA1c.

\begin{tabular}{|c|c|c|c|c|c|c|c|}
\hline \multirow{2}{*}{ HbAlc Groups } & \multirow{2}{*}{$\begin{array}{c}\text { IGT/IFG } \\
0\end{array}$} & \multicolumn{5}{|c|}{ Quintiles of glycated haemoglobin in T2D patients } & \multirow{2}{*}{ Total } \\
\hline & & 1 & 2 & 3 & 4 & 5 & \\
\hline Number & 10 & 61 & 55 & 55 & 62 & 62 & 305 \\
\hline Age (yrs) & $41.1 \pm 19.4$ & $53.2 \pm 10.9^{*}$ & $53.3 \pm 12.3$ & $52.0 \pm 9.3$ & $50.3 \pm 10.6$ & $48.8 \pm 10.8$ & $51.1 \pm 11.4$ \\
\hline $\operatorname{Sex}(M / F)$ & $5 / 5$ & $42 / 19$ & $40 / 15$ & $36 / 19$ & $40 / 22$ & $45 / 17$ & 208/97 \\
\hline Body mass index $\left(\mathrm{kg} / \mathrm{m}^{2}\right)$ & $28.4 \pm 8.3$ & $25.7 \pm 3.1$ & $25.7 \pm 3.2$ & $25.9 \pm 3.5$ & $25.2 \pm 2.7$ & $23.9 \pm 3.5$ & $25.3 \pm 3.5$ \\
\hline Haemoglobin $(\mathrm{g} / \mathrm{L})$ & $137.3 \pm 13.9$ & $142.9 \pm 16.9$ & $144.6 \pm 14.6$ & $144.7 \pm 18.4$ & $144.7 \pm 13.2$ & $141.1 \pm 12.2$ & $143.4 \pm 15.1$ \\
\hline Fasting glucose $(\mathrm{mmol} / \mathrm{L})$ & $5.6 \pm 0.9$ & $7.8 \pm 1.8^{*}$ & $9.2 \pm 2.0^{*}$ & $9.2 \pm 1.5$ & $10.7 \pm 2.0^{*}$ & $11.1 \pm 2.5$ & $9.5 \pm 2.4$ \\
\hline $\mathrm{AUC}_{\text {total }}(\mathrm{mmol} / \mathrm{L} \cdot$ day $)$ & $0.57 \pm 0.45$ & $3.35 \pm 1.84^{*}$ & $4.63 \pm 2$ & $5.21 \pm 1.75$ & $6.50 \pm 2.29^{*}$ & $6.78 \pm 2.69$ & $5.16 \pm 2.60$ \\
\hline $\mathrm{AUC}_{\mathrm{FG}}(\mathrm{mmol} / \mathrm{L} \cdot$ day & $0.20 \pm 0.25$ & $1.61 \pm 1.49$ & $2.87 \pm 1$ & $2.84 \pm 1.44$ & $4.26 \pm 1.90^{*}$ & $4.51 \pm 2.38$ & $3.14 \pm 2.16$ \\
\hline $\mathrm{AUC}_{\mathrm{PG}}(\mathrm{mmol} / \mathrm{L} \cdot$ day $)$ & $0.43 \pm 0.43$ & $1.78 \pm 1.12^{*}$ & $1.79 \pm 0.96$ & $2.38 \pm 1.13$ & $2.25 \pm 1.12$ & $2.27 \pm 1.12$ & $2.04 \pm 1.14$ \\
\hline FG contribution (\%) & $7.73 \pm 14.69$ & $39.71 \pm 28.06^{*}$ & $56.72 \pm 24.27^{*}$ & $53.22 \pm 17.96$ & $64.08 \pm 16.32$ & $62.54 \pm 20.15$ & $53.76 \pm 24.64$ \\
\hline PG contribution (\%) & $92.27 \pm 14.69$ & $60.29 \pm 28.06^{*}$ & $43.28 \pm 24.27^{*}$ & $46.78 \pm 17.96$ & $35.92 \pm 16.32$ & $37.47 \pm 20.15$ & $46.24 \pm 24.64$ \\
\hline Mean glycated haemoglobin (\%) & $5.5 \pm 0.4$ & $7.3 \pm 0.5^{*}$ & $8.3 \pm 0.3^{*}$ & $9.1 \pm 0.2^{*}$ & $10.1 \pm 0.4^{*}$ & $12.1 \pm 0.9^{*}$ & $9.3 \pm 1.9$ \\
\hline $\begin{array}{l}\text { Range of glycated haemoglobin } \\
\text { (\%) }\end{array}$ & $4.9-6.0$ & $6.1-7.8$ & $7.9-8.7$ & $8.8-9.5$ & $9.6-10.9$ & $11.0-14.6$ & $4.9-14.6$ \\
\hline
\end{tabular}

Data are mean \pm SD. ${ }^{*}$ Significant differences from the lower quintile.

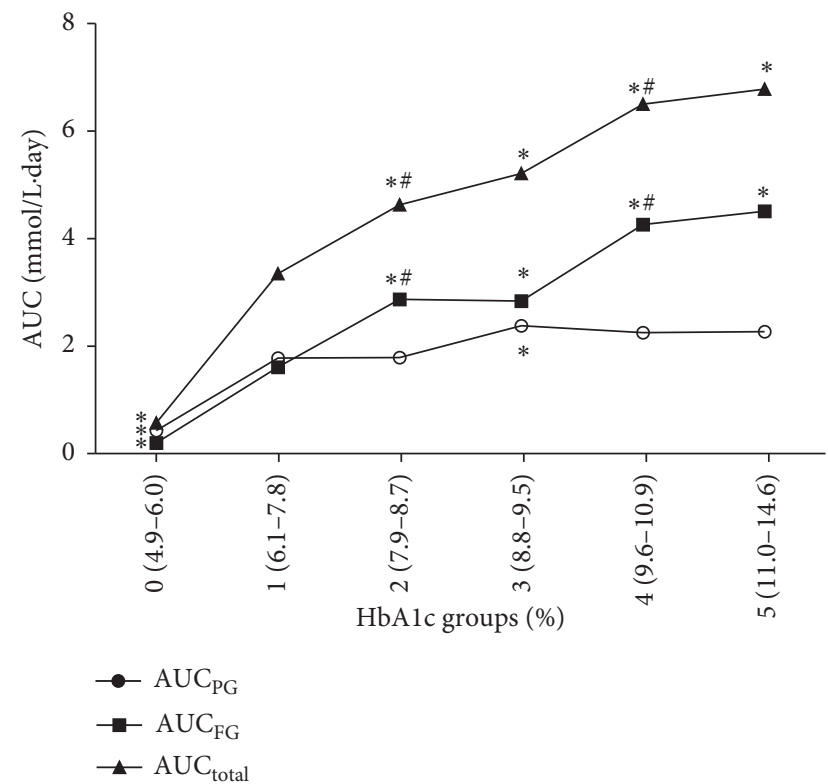

Figure 1: Area under the glucose curve derived from continuous glucose monitoring over groups of HbA1c. * Significant differences from group 1. "Significant differences from the lower one group. Area under the glucose curve $(\mathrm{AUC})_{\mathrm{FG}}=\mathrm{AUC}_{\text {total }}-\mathrm{AUC}_{\mathrm{PG}}$.

As shown in Figure 3, the relative contribution of FG had obviously positive correlation with $\mathrm{HbA1c}$. On the contrary, the relative contribution of PG was decreasing with increase in $\mathrm{HbAlc}$. The regression analysis between the contribution of FG or PG and HbAlc showed that the two regression curves jointed at the point of $\mathrm{HbAlc}=8.5 \%$, suggesting that FG contributes more than PG from $\mathrm{HbAlc}>8.5 \%$ and FG contributes less than PG when $\mathrm{HbA} 1 \mathrm{c}<8.5 \%$.

\section{Discussion}

The present study indicates that in newly diagnosed, drugnaïve T2D or IGT/IFG, FG had dominant contribution to

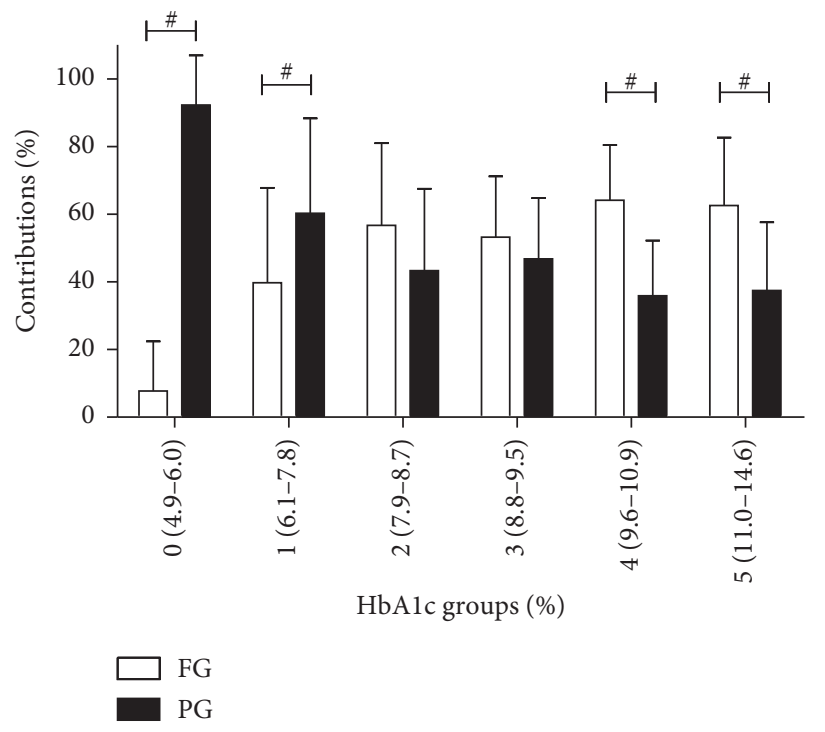

FIGURE 2: The relative contributions of fasting and postprandial glucose to overall glucose increment (\%) over groups of HbA1c. ${ }^{\#}$ Significant differences were observed between fasting and postprandial glucose (paired $t$-test). Area under the glucose curve $(\mathrm{AUC})_{\mathrm{FG}}=\mathrm{AUC}_{\text {total }}-\mathrm{AUC}_{\mathrm{PG}}$.

poorly controlled patients with $\mathrm{HbA1c}>8.5 \%$. Also, PG contributed more when $\mathrm{HbAlc}<8.5 \%$.

AUC $_{\mathrm{FG}}$ significantly increased from group 0 to 5 , especially in the upper groups, whereas $A \mathrm{UC}_{\mathrm{PG}}$ almost remained stable. It suggested that fasting hyperglycemia in the patients with higher $\mathrm{HbAlc}$ was the rising tide that would lift the postprandial hyperglycemia boat. When the fasting hyperglycemia decreased, the PG levels would drop down with the tide. Therefore, to eradicate hyperglycemia in poorly controlled patients with type 2 diabetes, the main principle of pharmacological intervention should be to choose therapeutic agents with an action primarily on basal glucose excursions. Although a recent review showed that PG strongly correlates with $\mathrm{HbAlc}$ or contributes 


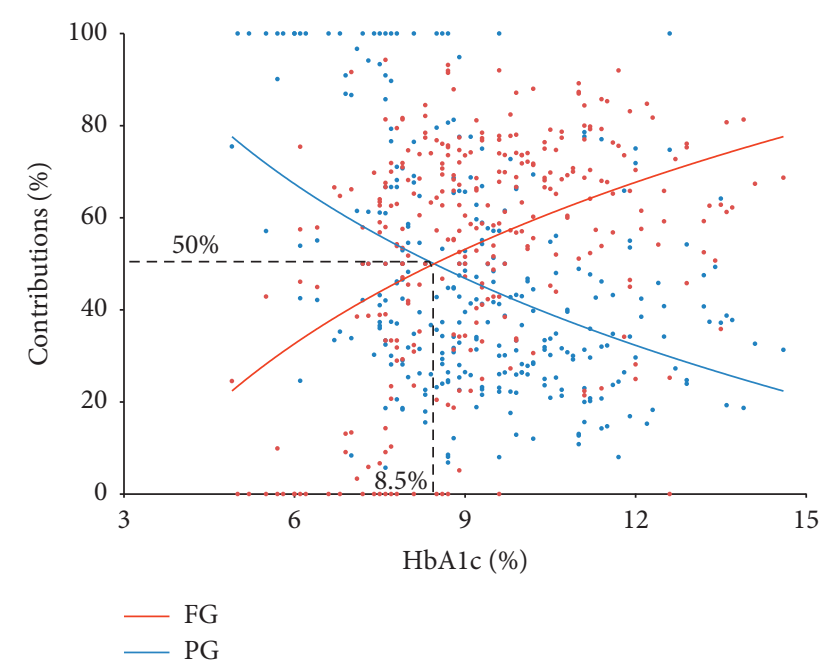

FIgURE 3: Correlation of the contribution of FG and PG and HbA1c.

significantly to overall glycemic control [17], FG should not be ignored when it comes to the management of patients with T2D. FG was also found to be more important than PG in diagnosed T2D treated by antihyperglycemic drugs with HbAlc $\geq 9.3 \%$ [6].

PG excursions in combination with FG play an important role in the contribution to overall hyperglycemia. Postprandial glucose was a strong predictor of cardiovascular events and all-cause mortality in a long-term follow-up [18]. Here, we found that the contribution of PG to overall hyperglycemia was higher than that of FG, when $\mathrm{HbAlc}$ ranged from $4.9 \%$ to $6.0 \%$ (mean: $5.5 \pm 0.4 \%$ ) in IGT/IFG patients and ranged from $6.1 \%$ to $7.8 \%$ (mean: $7.3 \pm 0.5 \%$ ) in patients with diabetes. Previous studies reported that mild hyperglycemia with $\mathrm{HbAlc}<7.3 \%$ or $7 \%$ or between 6.5 and $6.9 \%$ inclusive was mainly attributed to the elevation of PG $[6,19,20]$. All of these published studies suggested that the therapeutic measures of patients with mild hyperglycemia should be aimed at reducing postmeal glucose.

Kang et al. [19] performed CGMS in 59 newly diagnosed, drug-naive patients with $\mathrm{T} 2 \mathrm{D}$ patients and found that the contribution of PG was $57.78 \%$ which was significantly higher than FG when $\mathrm{HbAlc} \leq 7 \%$, whereas the contribution of FG was $79.58 \%$ significantly higher than PG when HbAlc $>9 \%$, and the contribution of FG and PG was equal with $\mathrm{HbAlc}$ between 7 and $9 \%$. However, the study sample was small. Here, in a larger population, we found similar association between the contribution of FG and PG and HbAlc. More importantly, we showed that FG contributes more than PG from $\mathrm{HbAl} 1 \mathrm{c}>8.5 \%$ and FG contributes less than PG when $\mathrm{HbAlc}<8.5 \%$, providing a cut point for reference in clinical treatment.

In conclusion, our results indicate that in drug-naïve, Chinese patients with T2D or IGT/IFG, from mild to severe hyperglycemia, the predominant contribution to $\mathrm{HbAlc}$ changed from $\mathrm{PG}$ to $\mathrm{FG}$ with the changing point at $\mathrm{HbAl}=8.5 \%$. This finding may aid doctors in formulating effective therapeutic plans according to the level of HbAlc.

\section{Data Availability}

The data used to support the findings of this study are available from the corresponding author upon request.

\section{Disclosure}

Rengna Yan, Yun $\mathrm{Hu}$, and Fengfei Li are the co-first authors.

\section{Conflicts of Interest}

The authors declare no conflicts of interest.

\section{Authors' Contributions}

JHM, XFS, KOL, and LY conceived and designed the experiments. XHX and YZ performed the experiments. RNY analyzed the data. YH, FFL, LLJ, and JW contributed reagents/materials/analysis tools. RNY wrote the paper.

\section{Acknowledgments}

This study was supported by National Key R\&D Program of China (no. 2018YFC1314102) and Jiangsu Provincial Special Program of Medical Science (BL2014010).

\section{References}

[1] American Diabetes Association, "Standards of medical care in diabetes-2009," Diabetes Care, vol. 32, no. 1, pp. S13-S61, 2009.

[2] UK Prospective Diabetes Study (UKPDS) Group, "Intensive blood-glucose control with sulphonylureas or insulin compared with conventional treatment and risk of complications in patients with type 2 diabetes (UKPDS 33)," The Lancet, vol. 352, no. 9131, pp. 837-853, 1998.

[3] The Diabetes Control and Complications Trial Research Group, "The relationship of glycemic exposure (HbAlc) to the risk of development and progression of retinopathy in the diabetes control and complications trial," Diabetes, vol. 44, no. 8, pp. 968-983, 1995.

[4] S. A. Imran, R. Rabasa-Lhoret, and S. Ross, "Targets for glycemic control," Canadian Journal of Diabetes, vol. 37, no. 1, pp. S394-S397, 2013.

[5] I. M. Stratton, A. I. Adler, H. A. Neil et al., "Association of glycaemia with macrovascular and microvascular complications of type 2 diabetes (UKPDS 35): prospective observational study," BMJ, vol. 321, no. 7258, pp. 405-412, 2000.

[6] L. Monnier, H. Lapinski, and C. Colette, "Contributions of fasting and postprandial plasma glucose increments to the overall diurnal hyperglycemia of type 2 diabetic patients: variations with increasing levels of HbA1c," Diabetes Care, vol. 26, no. 3, pp. 881-885, 2003.

[7] H. Shimizu, Y. Uehara, S. Okada, and M. Mori, "Contribution of fasting and postprandial hyperglycemia to hemoglobin A1c in insulin-treated Japanese diabetic patients," Endocrine Journal, vol. 55, no. 4, pp. 753-756, 2008.

[8] H. J. Woerle, C. Neumann, S. Zschau et al., "Impact of fasting and postprandial glycemia on overall glycemic control in type 2 diabetes Importance of postprandial glycemia to achieve target HbA1c levels," Diabetes Research and Clinical Practice, vol. 77, no. 2, pp. 280-285, 2007. 
[9] R. Peter, S. D. Luzio, G. Dunseath, V. Pauvaday, N. Mustafa, and D. R. Owens, "Relationship between HbAlc and indices of glucose tolerance derived from a standardized meal test in newly diagnosed treatment naive subjects with type 2 diabetes," Diabetic Medicine, vol. 23, no. 9, pp. 990-995, 2006.

[10] W. H. Li, X. H. Xiao, Q. Sun, G. H. Yang, and H. Wang, "Relationship between hemoglobin A1c and blood glucose throughout the day in well-glycemic-controlled medical nutrition therapy alone type 2 diabetic patients," Chinese Medical Sciences Journal = Chung-Kuo I Hsueh K'o Hsueh Tsa Chih/Chinese Academy of Medical Sciences, vol. 21, no. 2, pp. 90-94, 2006.

[11] R. Peter, G. Dunseath, S. D. Luzio, R. Chudleigh, S. R. Choudhury, and D. R. Owens, "Relative and absolute contributions of postprandial and fasting plasma glucose to daytime hyperglycaemia and $\mathrm{HbAlcin}$ subjects with type 2 diabetes," Diabetic Medicine, vol. 26, no. 10, pp. 974-980, 2009.

[12] K. Kikuchi, U. Nezu, J. Shirakawa et al., "Correlations of fasting and postprandial blood glucose increments to the overall diurnal hyperglycemic status in type 2 diabetic patients: variations with levels of HbA1c," Endocrine Journal, vol. 57, no. 3, pp. 259-266, 2010.

[13] M. Riddle, G. Umpierrez, A. DiGenio, R. Zhou, and J. Rosenstock, "Contributions of basal and postprandial hyperglycemia over a wide range of A1C levels before and after treatment intensification in type 2 diabetes," Diabetes Care, vol. 34, no. 12, pp. 2508-2514, 2011.

[14] J.-S. Wang, S.-T. Tu, I.-T. Lee et al., "Contribution of postprandial glucose to excess hyperglycaemia in Asian type 2 diabetic patients using continuous glucose monitoring," $D i$ abetes/Metabolism Research and Reviews, vol. 27, no. 1, pp. 79-84, 2011.

[15] K. G. M. M. Alberti, P. Z. Zimmet, and WHO Consultation, "Definition, diagnosis and classification of diabetes mellitus and its complications. Part 1: diagnosis and classification of diabetes mellitus. Provisional report of a WHO Consultation," Diabetic Medicine, vol. 15, no. 7, pp. 539-553, 1998.

[16] J. Mastrototaro, "The MiniMed continuous glucose monitoring system (CGMS)," Journal of Pediatric Endocrinology \& Metabolism: JPEM, vol. 12, no. 3, pp. 751-758, 1999.

[17] E. B. Ketema and K. T. Kibret, "Correlation of fasting and postprandial plasma glucose with HbA1c in assessing glycemic control; systematic review and meta-analysis," Archives of Public Health/Archives Belges de Sante Publique, vol. 73, p. 43, 2015.

[18] F. Cavalot, A. Pagliarino, M. Valle et al., "Postprandial blood glucose predicts cardiovascular events and all-cause mortality in type 2 diabetes in a 14-year follow-up: lessons from the San Luigi Gonzaga diabetes study," Diabetes Care, vol. 34, no. 10, pp. 2237-2243, 2011.

[19] X. Kang, C. Wang, D. Chen et al., "Contributions of basal glucose and postprandial glucose concentrations to hemoglobin A1c in the newly diagnosed patients with type 2 diabetes-the preliminary study," Diabetes Technology \& Therapeutics, vol. 17, no. 7, pp. 445-448, 2015.

[20] L. Monnier, C. Colette, S. Dejager, and D. Owens, "Residual dysglycemia when at target $\mathrm{HbA}(1 \mathrm{c})$ of $7 \%(53 \mathrm{mmol} / \mathrm{mol})$ in persons with type 2 diabetes," Diabetes Research and Clinical Practice, vol. 104, no. 3, pp. 370-375, 2014. 


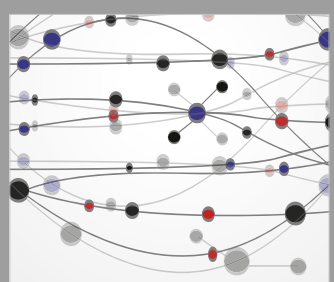

The Scientific World Journal
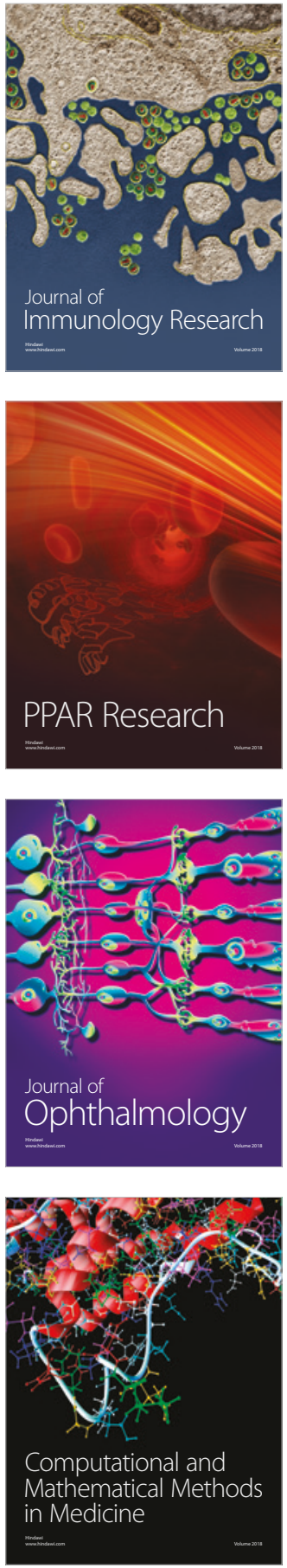

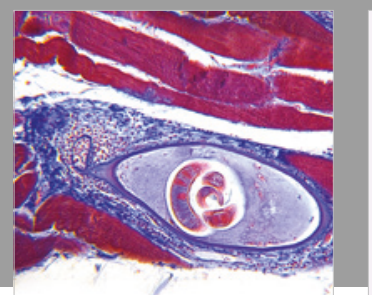

Gastroenterology Research and Practice

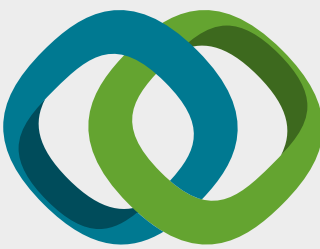

\section{Hindawi}

Submit your manuscripts at

www.hindawi.com
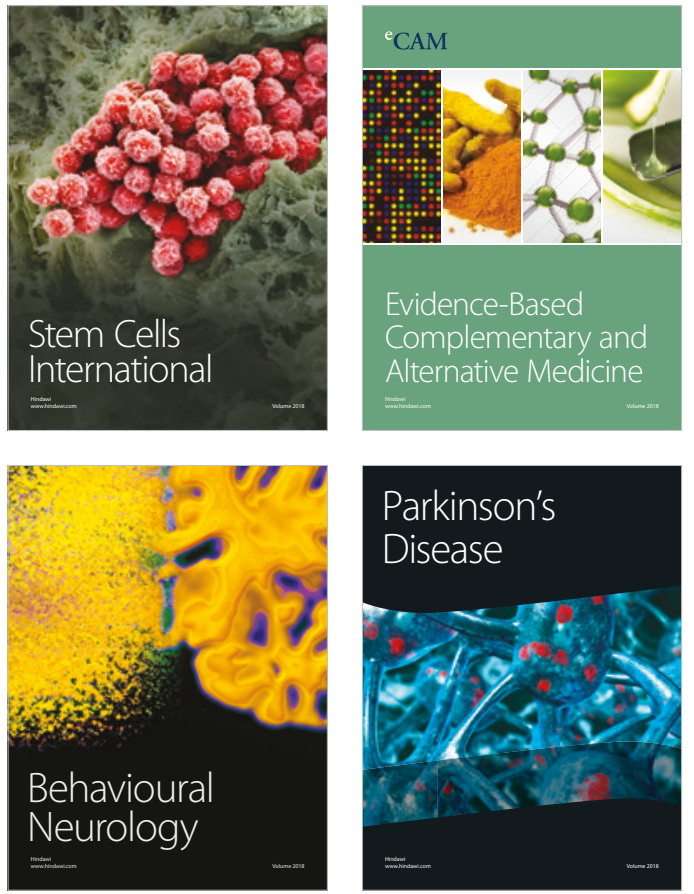

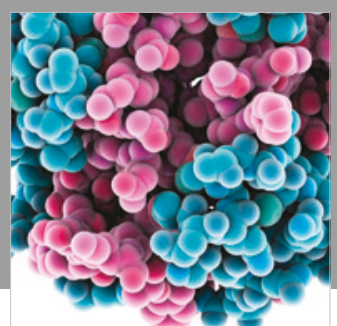

ournal of

Diabetes Research

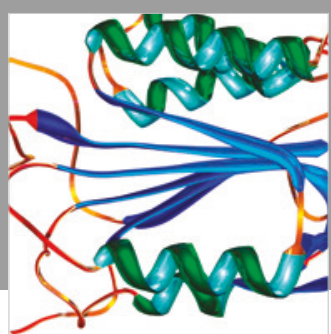

Disease Markers
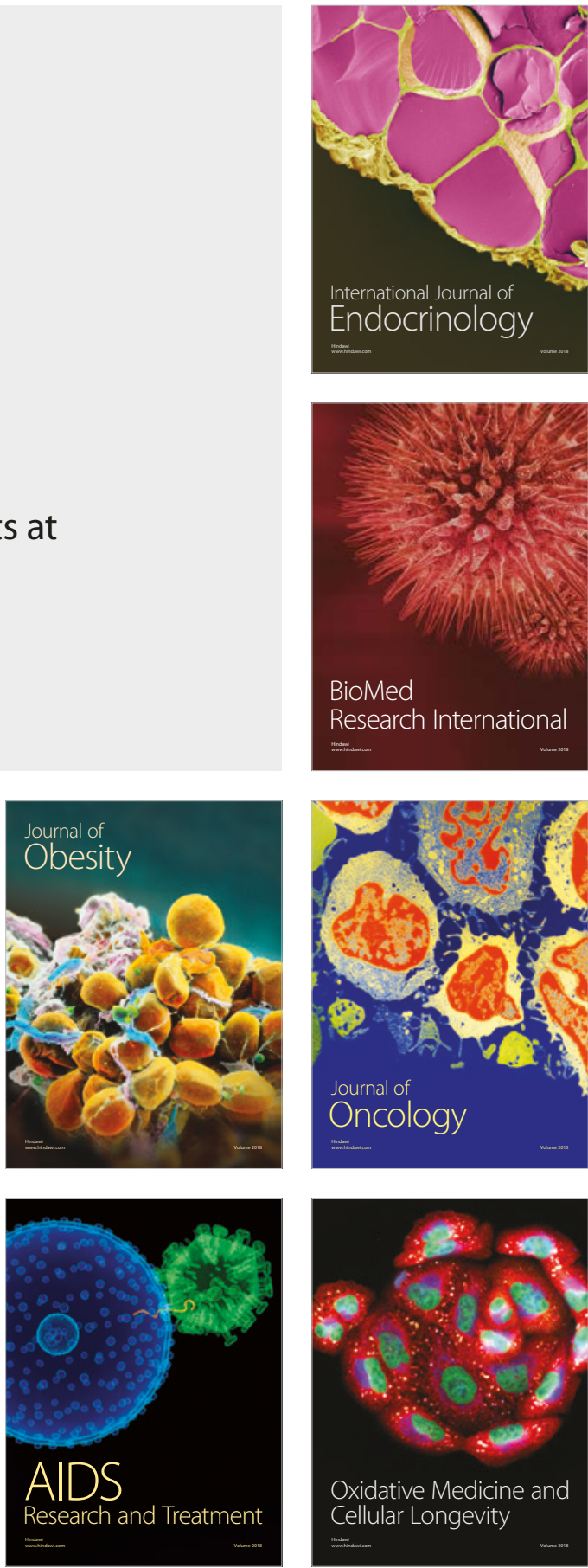